\title{
LiB Electrode Ageing Observed from PVdF Binder
}

\author{
Masamichi Sakaino1,2*, Syogo Hatake1, Yong Sun1, Fumio Morimoto ${ }^{3}$, Kenta Kirimoto ${ }^{4}$ \\ ${ }^{1}$ Department of Applied Science for Integrated System Engineering, Kyushu Institute of Technology, \\ Kitakyushu, Japan \\ ${ }^{2}$ Department of Vehicle Production Engineering, Nissan Motor Co., Ltd., Atsugi-City, Japan \\ ${ }^{3}$ Research Institute, Kyushu Kyoritsu University, Kitakyushu, Japan \\ ${ }^{4}$ Department of Electrical and Electronic Engineering, Kitakyushu National College of Technology, \\ Kitakyushu, Japan \\ Email: *sakaino-m@mail.nissan.co.jp
}

Received 23 June 2014; revised 25 July 2014; accepted 4 August 2014

Copyright (C) 2014 by authors and Scientific Research Publishing Inc.

This work is licensed under the Creative Commons Attribution International License (CC BY). http://creativecommons.org/licenses/by/4.0/

(c) (i) Open Access

\begin{abstract}
Ageing behaviors of the positive electrode of lithium ion battery are characterized by measuring mechanical properties of the electrode reeds, such as resonance frequency and internal friction, as a function of temperature. In the measurements of the electrode reeds with a sandwich structure of active material film and current collector of Al foil, two thermally-activated relaxation processes can be observed on the polyvinylidene difluoride binder in the active material film. Namely, a surface-related relaxation at $\sim 150 \mathrm{~K}$ and a relaxation corresponding to the $\beta$-phase transition at $\sim 240 \mathrm{~K}$ in the polymer binder can be observed at high signal/noise ratio. The resonance frequency decreases and the internal friction increases after charge/discharge cycling. The changes in activation energies of the relaxation processes also indicate that the measurement of mechanical properties of the positive electrode is an effective method for characterizing ageing behaviors of the positive electrode as a whole.
\end{abstract}

\section{Keywords}

LiB Positive Electrode, Mechanical Properties, Internal Friction, Resonance Frequency

\section{Introduction}

Elucidation of ageing mechanisms of lithium ion batteries (LiBs) has become an important issue because of their increasingly demanded applications [1]-[4]. Therefore, the knowledge of ageing reactions leading to either ca-

"Corresponding author. 
pacity fading or increase of resistance is mandatory to keep a long lifetime of LiBs. However, it is difficult to give an exhaustive picture of all the ageing reactions because of a large variety of LiBs. There are two types of ageing situation, charge/discharge cycling (cycling ageing) and storage (calendar ageing) [5]. The former ageing results in the effects in volume variations and concentration gradients, while the latter ageing results in the reactions of the active electrode materials [3] [6].

Recently, some studies have been focused on ageing effects on the cathode materials because the materials affect significantly performance parameters and lifetime of LiBs [7] [8]. The changes in the cathode due to the ageing processes are recognized as: (a) ageing of active materials, (b) degradations of binder and conducting agents, (c) corrosion of current collector, (d) oxidation of electrolyte composition and film formation on the surface of active materials, and (e) interaction of ageing products with negative electrode. These effects do not occur separately and therefore cannot be analyzed independently each other. In general, the ageing processes of the cathode materials can originate from changes in structure and chemical decomposition as well as film formation at the interface between active materials and electrolyte [9] [10].

Electrochemical impedance spectroscopy has been employed as a fast, non-destructive and reliable technique to elucidate ageing behaviors of $\mathrm{LiB}$ cells [11] [12]. In particular, it is effective in characterizing reaction processes occurring in the cells, such as changes of particle-to-particle contacting resistance [13] and charge- transfer resistance [14] [15] in active materials and electrolyte as well as through their interface. It is also sensitive to increase in cell impedance due to various reactions such as oxidation of conductive particles, binder decomposition, loss of contact to conductive particles, micro-cracking, structural disordering in active materials, and film formation on the surface of active materials. However, this technique cannot analyze directly the ageing behaviors of electrode or electrolyte, separately. Moreover, structural and compositional analysis techniques such as $\mathrm{x}$-ray diffraction, Raman scattering, IR absorption and TEM observation are used to local characterization of electrodes or separator, but cannot characterize the ageing behaviors of positive or negative electrode as a whole. In order to realize a balance between lifetimes of electrode, electrolyte and separator, it is necessary to provide a technique to separately measure ageing behaviors of these $\mathrm{LiB}$ parts.

Since elastic properties of materials depend sensitively on internal friction due to lattice distortion and its thermodynamic behaviors, elastic parameters can be anticipated as effective indicators for characterization of ageing behaviors of the LiB electrode as a whole.

In this study, we measured both resonance frequency and internal friction of positive-electrode reed samples as a function of temperature. The results indicated that the charge/discharge cycling causes decrease in the resonance frequency and increase in the internal friction of the positive electrode. Our results also indicated that mechanical parameter is an effective measure to characterize the ageing behaviors of the LiB electrodes. Finally, we discussed mechanisms of the internal friction on the positive electrode through comparison with the measurement results of the negative electrode.

\section{Experimental}

Two kinds of LiBs, not filled and filled with electrolyte, having dimensions of $230 \times 200 \times 7 \mathrm{~mm}^{3}$, were obtained from Nissan Motor Co., Ltd. The positive electrode of the un-filled battery was cut to the reed samples having dimensions of $5.0 \times 0.19 \times l \mathrm{~mm}^{3}$, where $l$ is $27,29,31$ and $39 \mathrm{~mm}$. Here, the length $l$ corresponds to resonance frequency of $75.8,64.7,53.3$ and $38.6 \mathrm{~Hz}$ at room temperature, respectively. On the other hand, the filled battery was prepared by charge/discharge for 150 cycles at $20 \%$ depth-of-discharge (DOD), and was opened in inert gas atmosphere. The positive electrode of the filled battery after the charge/discharge cycling was also cut to the reed samples with the same dimensions.

The positive electrode of the battery is composed of a sandwich structure of the active material film and current collector (aluminum foil) as shown in Figure 1(a). The active material was coated on either side of the $\mathrm{Al}$ foil at the same thickness of $80 \mu \mathrm{m}$ where the $\mathrm{Al}$ foil is $30 \mu \mathrm{m}$ thick. The active material film is composed of lithium manganese oxide $\left(\mathrm{LiMn}_{2} \mathrm{O}_{4}\right)$ and lithium nickel cobalt aluminum oxide $\left.(\mathrm{LiNiCoAlO})_{2}\right)$. These active materials were coated using polyvinylidene difluoride $\left(\mathrm{PVdF},-\mathrm{CH}_{2} \mathrm{CF}_{2}\right.$-) binder. In order to enhance conductivity of the PVdF binder, carbon black particles (3-500 nm in diameter) and graphite nanoplatelets were added into the binder as conducting fillers. Prior to the measurements of elastic parameters, the positive electrodes were characterized by compositional and structural analyses using transmission scanning electron microscope (TEM, JEM ARM200F) and electron probe micro analyzer (FE-EPMA, JXA-8530F).

The measurement system of the elastic parameters of the positive electrode is shown in Figure 1(b). The reed 
sample was set in a copper box equipped in a vacuum chamber under the residual gas pressure below $3 \times 10^{-4}$ $\mathrm{Pa}$. One end of the reed sample was fixed on the copper box to assure an electrical ground lead and to control its temperature. An alternating voltage with variable frequency and amplitude was applied to the free end of the sample to vibrate it at its resonance frequency.

The displacement of the free end of the reed sample during free decay vibration was measured using a laser/CCD camera system with $10 \mathrm{~nm}$ accuracy as a function of time. Temperature of the sample set in the copper box was changed from $100 \mathrm{~K}$ to $400 \mathrm{~K}$ with a rate of $0.2 \mathrm{Kmin}^{-1}$ and in a stepwise with $5.0 \mathrm{~K}$ step.

The amplitude $\mathrm{A}$ of the free end of the sample during the free decay vibration decreases exponentially with time $\mathrm{t}, \mathrm{A}=\mathrm{A}_{0} \exp (-\alpha \mathrm{t})$ due to an internal friction in the sample. Here, $\alpha$ is the decay constant. Internal friction $\mathrm{Q}^{-1}$ is determined as $\mathrm{Q}^{-1}=\alpha / \pi f$ where $f$ is the resonance frequency of the reed sample.

\section{Results and Discussion}

\subsection{Experimental Results}

Figure 2 shows the element mapping results on the surface of the active materials. The mapping patterns for Co and $\mathrm{Ni}$ elements are same, suggesting the Co and Ni elements form a compound. The mapping pattern of Mn appears to be reversed from that of Co or Ni. This result suggests that $\mathrm{Mn}$ forms another compound avoiding Co and Ni. Also, the overlap in the mapping patterns of $\mathrm{O}$ with that of $\mathrm{Mn}, \mathrm{Co}$ and $\mathrm{Ni}$ suggests the existence of manganese and cobalt/nickel oxides in the active materials. The mapping patterns of $\mathrm{C}$ and $\mathrm{F}$ elements are different from that of Mn, Co and Ni. F may come from the PVdF binder and C from both the PVdF and the carbon black in the binder.

The results of TEM observation and electron beam diffraction of the active materials of the positive electrode are shown in Figure 3. TEM images in both bright field and dark field mode are shown in Figure 3(a) and Figure 3(b). There are four types of areas in the images, $\mathrm{Mn}, \mathrm{Co} / \mathrm{Ni}, \mathrm{PVdF}$ and $\mathrm{Al}$ areas. It is confirmed in the TEM observation that the PVdF binder was filled into the space between $\mathrm{Mn}$ and $\mathrm{Co} / \mathrm{Ni}$ particles and $\mathrm{Al}$ foil. A large number of hollow voids with large surface area are observed in the PVdF binder area as seen in Figure 3(a) and Figure 3(b). The electron beam diffraction patterns from the $\mathrm{Mn}$ and $\mathrm{Co} / \mathrm{Ni}$ areas are shown in Figure 3(c) and Figure 3(d). The $\mathrm{Mn}$ and $\mathrm{Co} / \mathrm{Ni}$ particles are confirmed to have crystallographic structures of $\mathrm{LiMn}_{2} \mathrm{O}_{4}$ and Li$\mathrm{NiCoAlO}_{2}$ based on these electron beam diffraction patterns.

The element distributions on the area in Figure 3, mapped by energy dispersive x-ray spectroscopy (EDX) are shown in Figure 4. The result of element mapping using EDX indicates that the particles of manganese oxide as well as cobalt/nickel oxide are coated by the PVdF binder and are deposited on the surface of the Al foil. The results for the element distribution in the positive electrode are consistent to that measured by EPMA as shown in Figure 2.

We also confirmed the presence of lithium atom in the active material by electron energy loss spectroscopy (EELS) on selected area electron diffraction (SAED) mode, and the result obtained is shown in Figure 5. The lithium atom is detected at the $\mathrm{LiMn}_{2} \mathrm{O}_{4}$ area only.

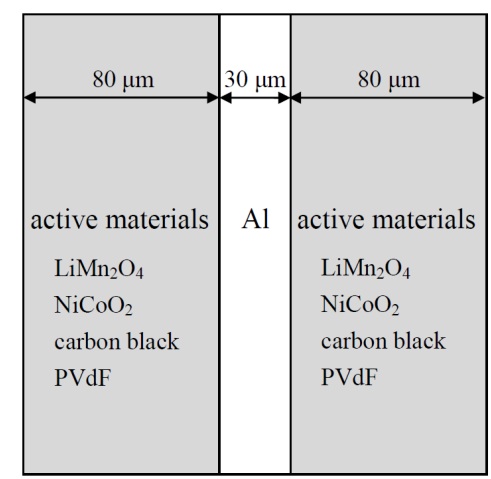

(a)

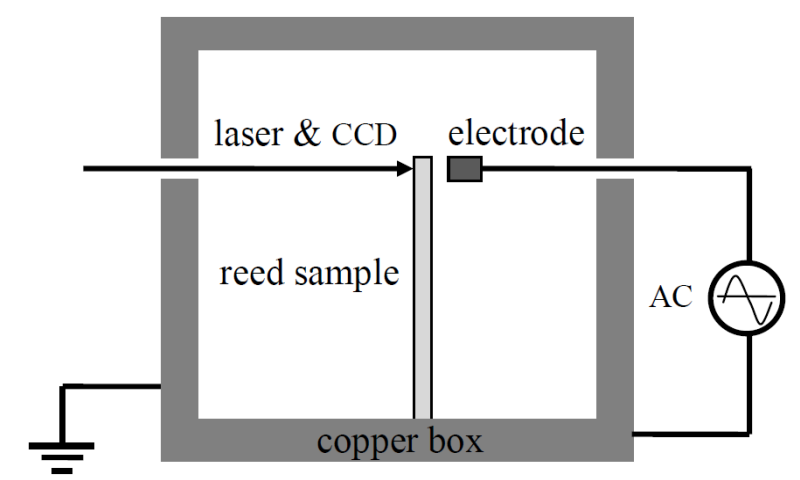

(b)

Figure 1. (a) Schematic diagram of the positive-electrode structure; (b) Elastic parameter measurement system of the positive-electrode reed sample. 


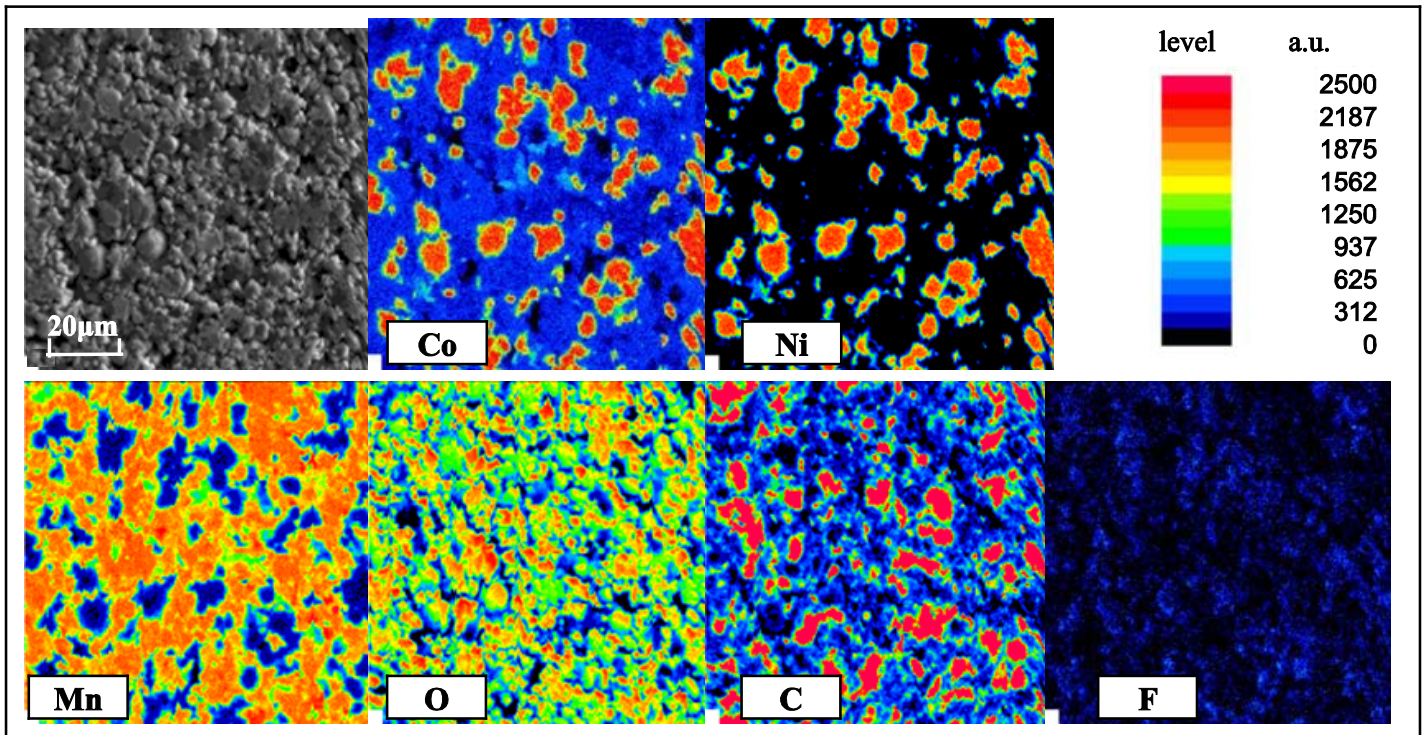

Figure 2. Element mappings on the surface of the active materials of the positive electrode.

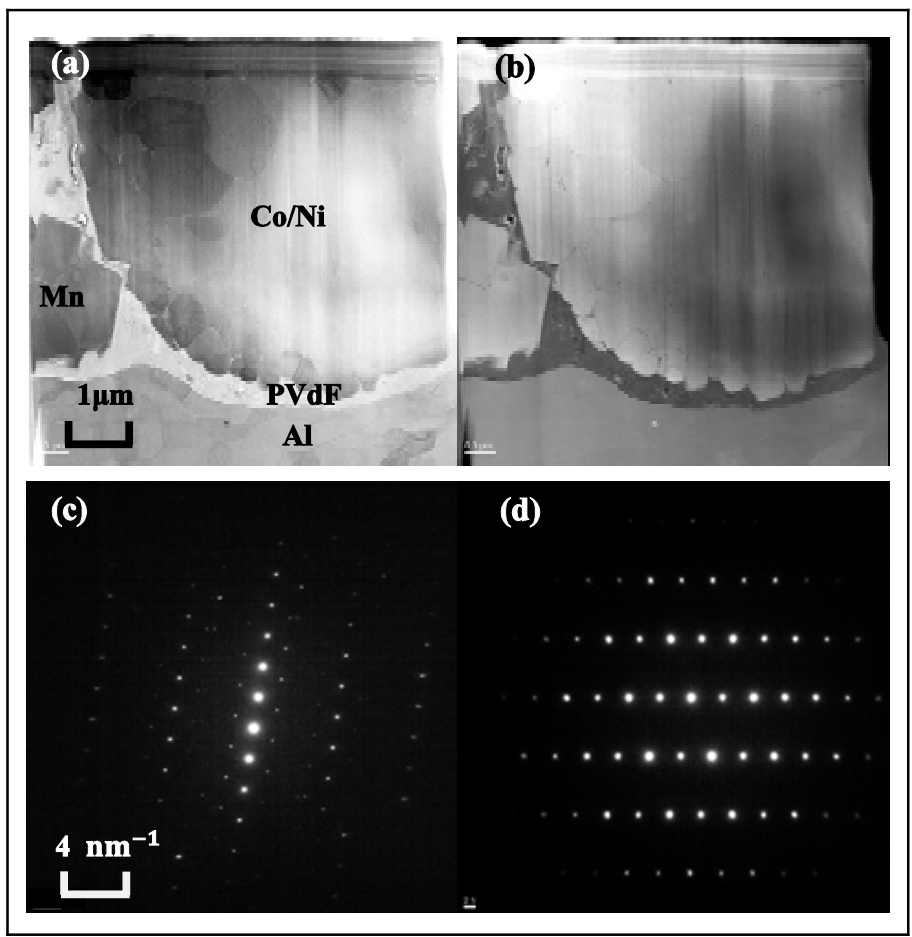

Figure 3. EM images: (a) in bright field mode, (b) in dark field mode as well as electron beam diffraction patterns, (c) in $\mathrm{Mn}$ area, and (d) in $\mathrm{Co} / \mathrm{Ni}$ area at the active materials/Al foil interface of the positive electrode.

High-resolution transmission electron microscopy (HRTEM) image of the PVdF binder is shown in Figure 6. The carbon black crystals can be observed in the PVdF binder, and a graphite-like crystal particle with spacing of $0.335 \mathrm{~nm}$ can be seen around the center area in the figure.

Based on the above experimental results, we can conclude that the active materials of the positive electrodes are composed of $\mathrm{LiMn}_{2} \mathrm{O}_{4}$ and $\mathrm{LiNiCoAlO}_{2}$ micro-crystals. These micro-crystals are coated by the PVdF binder containing carbon black which improves electrical conductivity of the PVdF binder. 


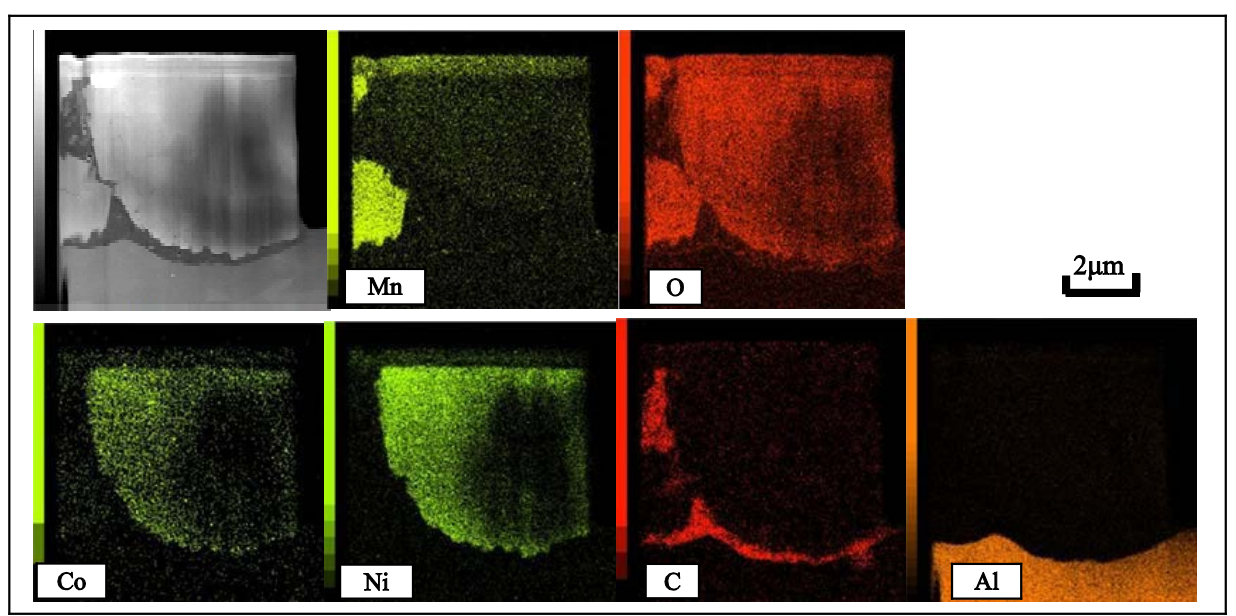

Figure 4. Element mappings at the active materials/Al foil interface by using EDX spectroscopy.

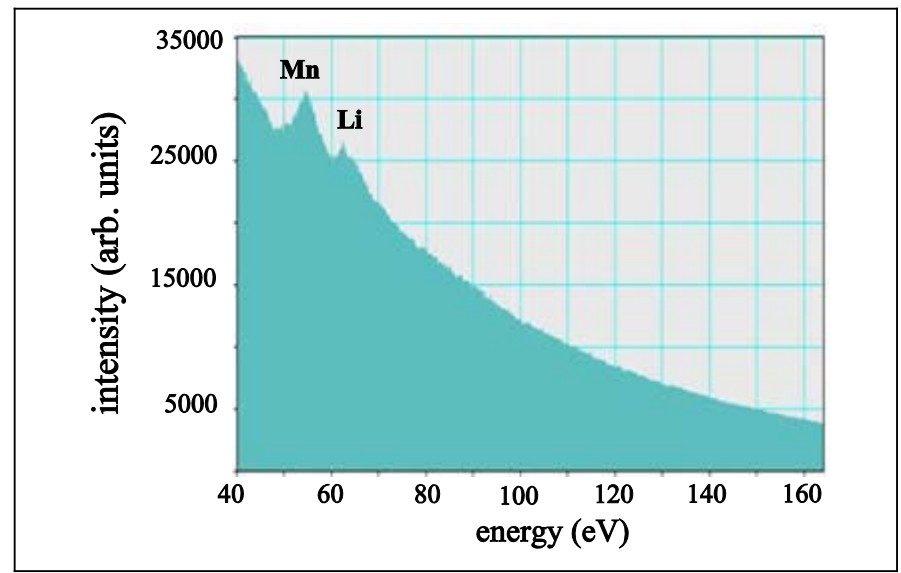

Figure 5. EELS spectrum on selected area electron diffraction mode in the manganese oxide area at the active materials/Al foil interface of the positive electrode.

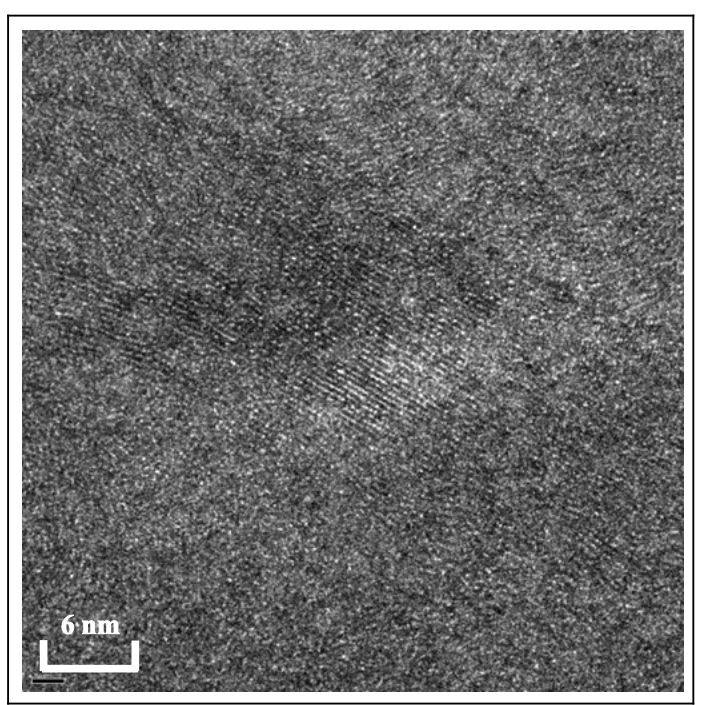

Figure 6. HRTEM image of the PVdF binder in the active materials of the positive electrode. 
The resonance frequencies of the positive-electrode reed samples with lengths of 27, 29, 31 and $39 \mathrm{~mm}$ are plotted as a function of temperature in Figure 7. The resonance frequency decreases with increasing temperature. A sharp decrease of the frequencies appears at $\sim 150 \mathrm{~K}$ and $\sim 240 \mathrm{~K}$ for all reed samples. In general, the sharp decrease in the temperature-dependent resonance frequency results in a peak on the temperature-dependent internal friction.

The internal frictions of the positive electrode samples are plotted in Figure 8 as a function of temperature. The internal friction $\mathrm{Q}^{-1}$ changes strongly with temperature in the range of $100-400 \mathrm{~K}$. At high temperature side, the increase in $\mathrm{Q}^{-1}$ may be related to a $\alpha$-relaxation process occurring in the PVdF binder at $413 \mathrm{~K}$ [16]. Two $\mathrm{Q}^{-1}$ peaks at low temperature side at $\sim 150 \mathrm{~K}$ and $\sim 240 \mathrm{~K}$ correspond to sharp decreases in the temperature-dependent resonance frequencies of the samples. The peaks are symmetric and sharp. It may be due to a surface-related relaxation (s-relaxation) process for the peak at $\sim 150 \mathrm{~K}$ as well as a $\beta$-relaxation process in the PVdF binder for the peak at $\sim 240 \mathrm{~K}$, respectively [17]. These relaxations are thermally activated processes because the internal friction peaks shift to higher temperatures with increasing resonance frequency.

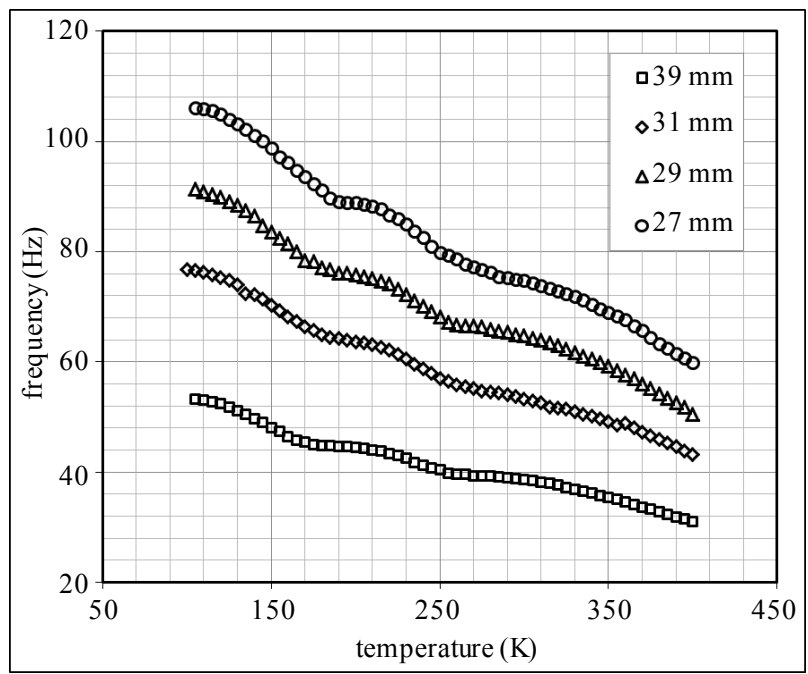

Figure 7. Resonance frequencies of the positive-electrode reed samples with lengths of $27,29,31$ and $39 \mathrm{~mm}$ as a function of temperature.

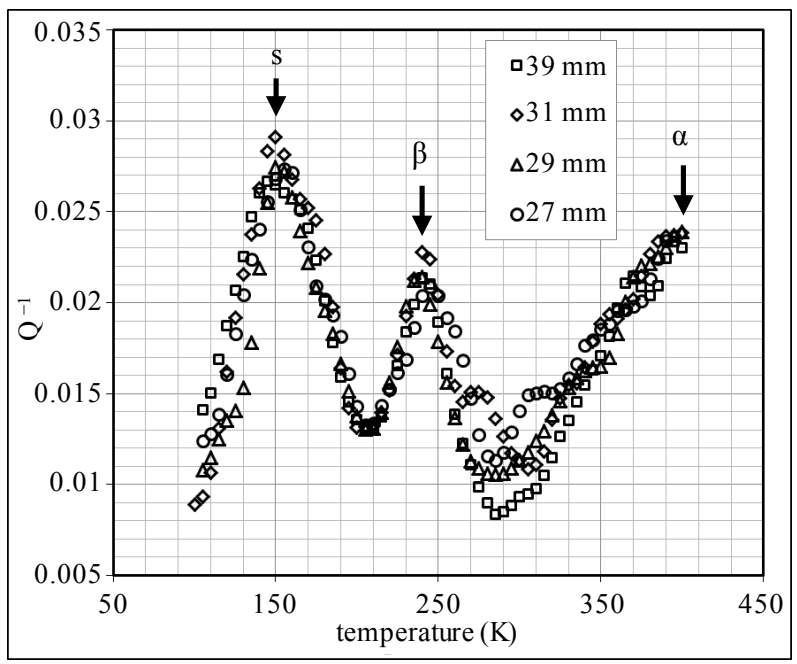

Figure 8. Internal frictions of the positive-electrode reed samples with lengths of $27,29,31$ and $39 \mathrm{~mm}$ as a function of temperature. 
To obtain the physical parameters of these thermally activated processes we tried to explain the internal friction by means of the Debye model. The contribution of a relaxation process to the internal friction is given by $\mathrm{Q}^{-1}=\varphi \omega \tau /\left(1+\omega^{2} \tau^{2}\right)$, where $\varphi$ is a constant corresponding to the relaxation strength that not depends on temperature, $f=\omega / 2 \pi$ the resonance frequency of the reed sample and $\tau$ the relaxation time of the thermally activated process. Here, the $\tau$ generally follows an Arrhenius law, $\tau^{-1}=\tau_{0}^{-1} \exp \left(-\mathrm{E}_{\mathrm{a}} / \mathrm{kT}\right)$ where $\tau_{0}$ is a constant and $\mathrm{E}_{\mathrm{a}}$ the activation energy of the thermally activated process. When the resonance frequency of the reed sample is equal to $\tau^{-1}, \omega \tau=1$, through changing temperature, the internal friction $\mathrm{Q}^{-1}$ becomes maximum. The Arrhenius plots of the relaxation rate, $\tau^{-1}$, for two thermally activated processes at $\sim 150 \mathrm{~K}$ and $\sim 240$ $\mathrm{K}$ are shown in Figure 9 as a function of inverse temperature. We obtain two activation energies of $208 \mathrm{meV}$ for the process at $\sim 240 \mathrm{~K}$ and $104 \mathrm{meV}$ for the process at $\sim 150 \mathrm{~K}$ from slopes of the Arrhenius plots in this figure. The results are consistent with the symmetry of two $\mathrm{Q}^{-1}$ peaks in Figure 8 that these processes result from simple Debye relaxation with single $\mathrm{E}_{\mathrm{a}}$ and $\tau$.

The internal friction of the positive electrode would be occurred in the $\mathrm{LiMn}_{2} \mathrm{O}_{4}$ and $\mathrm{LiNiCoAlO}_{2}$ microcrystals, the PVdF binder, the carbon black and the $\mathrm{Al}$ foil. In order to clarify the origins of the internal friction, it is significant to characterize the effects of charge/discharge process on the internal friction. We have measured the internal friction of the positive electrode after the charge/discharge of 150 cycles. The charge/discharge cycling, the voltage profile is shown in Figure 10. The charging was carried out at a constant current (CC) of $3 \mathrm{~A}, 2 \mathrm{~A}, 1$ $\mathrm{A}$ and $0.5 \mathrm{~A}$, respectively, for a limit cell voltage of $4.15 \mathrm{~V}$ and a maximum charging time of $3.5 \mathrm{hr}$, as marked by " $\mathrm{C}$ " ranges in the figure. On the other hand, the discharging was executed through a resistance of $1.1 \Omega$ at room temperature for $20 \% \mathrm{DOD}$, corresponding to a minimum cell voltage of $3.84 \mathrm{~V}$, as marked by "D" ranges in the figure.

After the charge/discharge of 150 cycles the battery was opened and its positive electrode was washed using $\mathrm{N}$-methyl-2-pyrrolidone solvent in an inert gas atmosphere in order to make the electrolyte clean. The positive electrode which had been washed was cut to reed samples with lengths of 27, 29, 31 and $39 \mathrm{~mm}$, respectively. The resonance frequencies of the reed sample with length of $39 \mathrm{~mm}$ before and after the charge/discharge cycling are plotted in Figure 11 as a function of temperature. The resonance frequency decreases with increasing temperature, and drops markedly at temperatures of $\sim 150 \mathrm{~K}$ and $\sim 240 \mathrm{~K}$. For example, the resonance frequencies decrease $17 \%$ at $150 \mathrm{~K}$ and $19 \%$ at $240 \mathrm{~K}$ after the charge/discharge cycling.

The internal friction of the positive electrode is also sensitive to the charge/discharge process. The internal frictions of the reed sample with length of $39 \mathrm{~mm}$ before and after the charge/discharge of 150 cycles are shown in Figure 12 as a function of temperature. Changes on the internal friction after the charge/discharge cycling, the increase of the $\mathrm{Q}^{-1}$ value and the shift of the $\mathrm{Q}^{-1}$ peaks, can be seen in the figure. Intensities of the $\mathrm{Q}^{-1}$ peaks at $150 \mathrm{~K}$ and $240 \mathrm{~K}$ increase $40 \%$ and $16 \%$ after the charge/discharge cycling. The increase in the $\mathrm{Q}^{-1}$

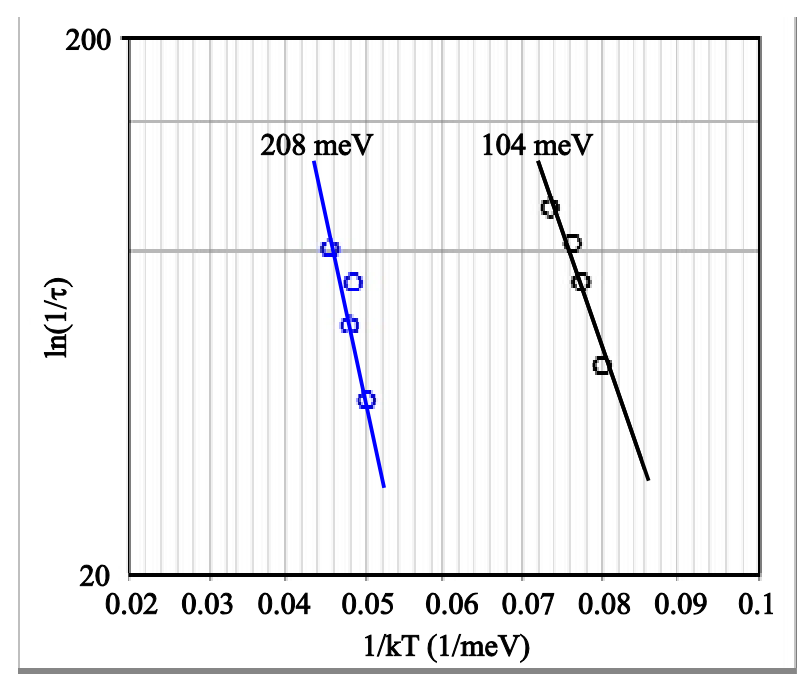

Figure 9. Arrhenius plots of the relaxation rate, $\tau^{-1}$, for two relaxation processes occurring at $\sim 150 \mathrm{~K}$ and $\sim 240 \mathrm{~K}$ with activation energies of $104 \mathrm{meV}$ and $208 \mathrm{meV}$. 


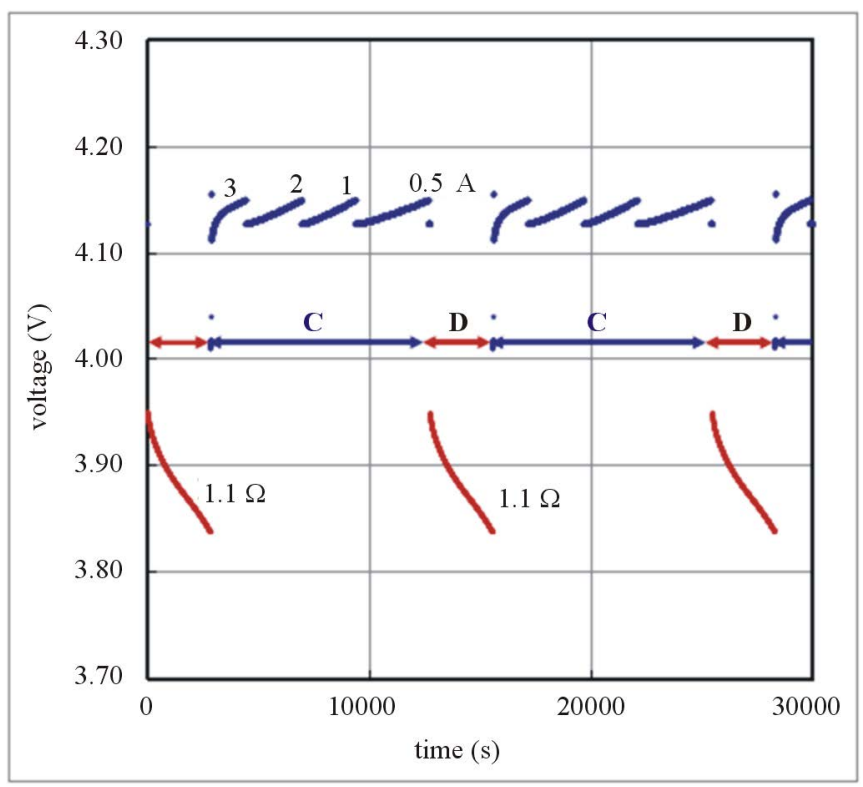

Figure 10. The voltage profile of the $\mathrm{LiB}$ cell during the charge/ discharge cycling. The " $\mathrm{C}$ " range corresponds to the charge process at constant currents of 3,2,1 and $0.5 \mathrm{~A}$, and the " $\mathrm{D}$ " range corresponds to the discharge process for decreasing cell voltage from $4.15 \mathrm{~V}$ to $3.84 \mathrm{~V}$ through a resistance of $1.1 \Omega$.

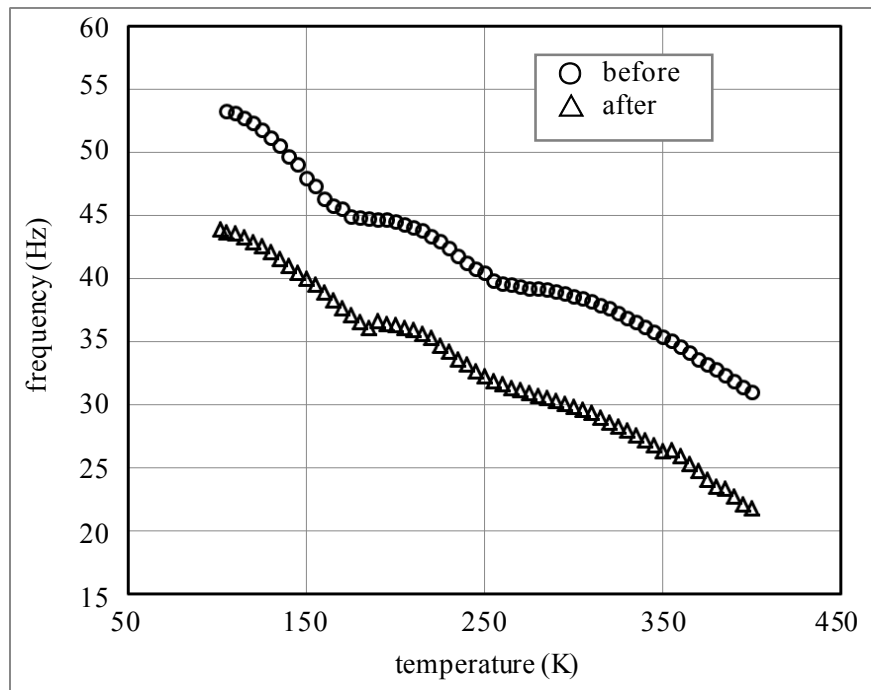

Figure 11. Resonance frequencies of the positive-electrode reed samples with length of $39 \mathrm{~mm}$ before and after the charge/discharge of 150 cycles as a function of temperature.

value indicates that stronger Debye absorption appears in the sample after the charge/discharge cycling. It suggests a structure change occurred on molecular level of the active materials. It is well known that the active materials absorb the electrolyte at first charge/discharge cycle of the LiB.

Shifts of the $\mathrm{Q}^{-1}$ peaks suggest a change in activation energies of the thermally activated relaxation processes. The Arrhenius plots of the relaxation rate, $\tau^{-1}$, for the processes at $\sim 150 \mathrm{~K}$ and $\sim 240 \mathrm{~K}$ after the charge/discharge of 150 cycles are shown in Figure 13 as a function of inverse temperature. The activation energy is $901 \mathrm{meV}$ for the process at $\sim 240 \mathrm{~K}$ and $289 \mathrm{meV}$ for the process at $\sim 150 \mathrm{~K}$, respectively. These activation energies become large after the charge/discharge cycling. 


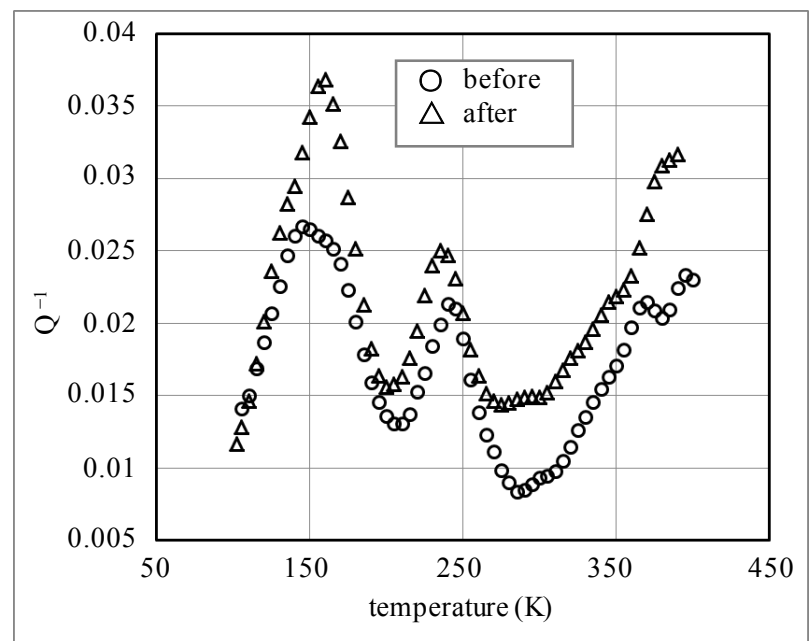

Figure 12. Internal frictions of the positive-electrode reed samples with length of $39 \mathrm{~mm}$ before and after the charge/discharge of 150 cycles as a function of temperature.

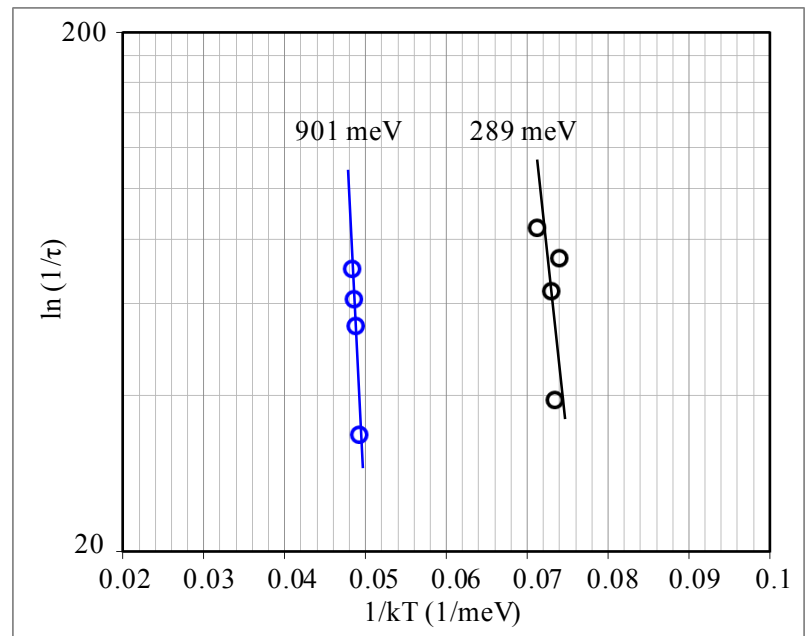

Figure 13. Arrhenius plots of the relaxation rate, $\tau^{-1}$, for two relaxation processes occurred at $\sim 150 \mathrm{~K}$ and $\sim 240 \mathrm{~K}$ in the reed samples after the charge/discharge cycling. Activation energies of $289 \mathrm{meV}$ and $901 \mathrm{meV}$ are observed in the processes at $\sim 150 \mathrm{~K}$ and $\sim 240 \mathrm{~K}$.

In order to clarify these relaxation processes which may occur in the active materials, the binder or the $\mathrm{Al}$ foil, the internal friction of the negative electrode of the same cell after the charge/discharge of 150 cycles was also measured. The negative electrode has a sandwich structure of the active material film and current collector (copper foil), similar to that of the positive electrode as shown in Figure 1(a). Their thicknesses were $60 \mu \mathrm{m}$ for the active material films and $20 \mu \mathrm{m}$ for the $\mathrm{Cu}$ foil. The active materials of the negative electrode are mainly composed of graphite nanoplatelets, carbon black and PVdF binder. The internal frictions of both negative and positive electrode reeds with the same length of $31 \mathrm{~mm}$ are plotted in Figure 14 as a function of temperature. Unlike the results of the positive electrode samples, two new peaks at $\sim 190 \mathrm{~K}$ and $\sim 370 \mathrm{~K}$ are also observed in addition to the peaks at $\sim 150 \mathrm{~K}$ and $\sim 240 \mathrm{~K}$. The peak at $\sim 150 \mathrm{~K}$ is weak and that at $\sim 240 \mathrm{~K}$ is broad. It may be related to a $\gamma$-relaxation process for the peak at $\sim 190 \mathrm{~K}$ and an $\alpha$-relaxation process at $\sim 370 \mathrm{~K}$ in the PVdF binder.

We are now in the position to discuss the ageing behaviors and the mechanisms of internal friction appeared in the positive electrode on the basis of the above experimental results. 


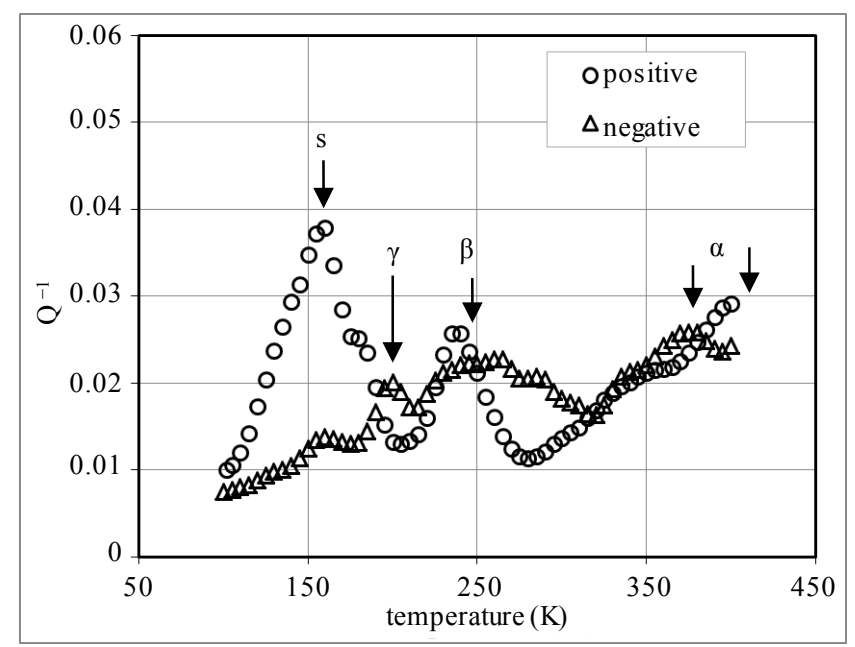

Figure 14. Internal frictions of both positive and negative electrode reeds with length of $31 \mathrm{~mm}$ as a function of temperature.

\subsection{Discussion on Internal Frictions}

\subsubsection{Internal Friction on PVdF Binder}

The PVdF is a semi-crystalline polymer having $\alpha, \beta, \gamma$ and $\delta$ crystalline phases [18]-[22]. The $\alpha$ crystalline structure contains trans-gauche-trans-gauche chain conformations in a monoclinic lattice, and is obtained by melt crystallization at temperatures below $433 \mathrm{~K}$ [23] [24]. The $\beta$ crystalline phase can be produced through mechanically drawing $\alpha$ phase materials [23] [25]. The $\gamma$ crystalline phase can be obtained by crystallization from melt at high pressure or by crystallization from certain solutions such as dimethylacetamide $\left(\mathrm{CH}_{3} \mathrm{CON}\left(\mathrm{CH}_{3}\right)_{2}\right)$ and dimethylsufoxide $\left(\left(\mathrm{CH}_{3}\right)_{2} \mathrm{SO}\right)$ [18] [21] [25]. The $\delta$ crystalline phase is usually obtained by poling $\alpha$ phase under high electric field [18] [19].

In internal friction studies of the PVdF polymer, a number of relaxation processes corresponding to the $\alpha, \beta$ and $\gamma$ phase transitions have been observed. The $\alpha$-relaxation is related to thermal movement processes of the PVdF molecule near the crystalline melting point [16] [17] [26]-[32]. The $\beta$-relaxation is due to micro-Brownian motions of the linear chain segments close to the glass transition temperature [16] [17] [28]-[32]. Also, the $\gamma$-relaxation is due to thermally-activated local molecular oscillations in the amorphous phase of the PVdF polymer [16] [17] [28].

Low-temperature internal friction on the PVdF polymer has been reported by Callens et al. [16] [17]. They measured the internal friction spectra of the PVdF polymer by using a torsion pendulum technique. Nine peaks were observed on temperature-dependent internal friction spectra of the PVdF polymer at temperatures of $\sim 140$, $\sim 190, \sim 220, \sim 236, \sim 270, \sim 330, \sim 350, \sim 386$ and $\sim 413 \mathrm{~K}$ in the range of $70-450 \mathrm{~K}$. The internal friction process at $\sim 140 \mathrm{~K}$ corresponds to a surface-related relaxation process because its relaxation rate is several times as large for PVdF fiber sample as for PVdF bulk sample. In this study as observed in Figure 3, there are a large number of hollow voids in the PVdF binder. The surface of the hollow voids and the interface between the active materials and the PVdF binder can be involved to the surface-related relaxation process. The peak at $\sim 190 \mathrm{~K}$ corresponds to the $\gamma$-relaxation which can be understood in terms of the cranckshaft or local-mode molecular models based upon molecular motions of small, isolated chain segments within amorphous phase in the PVdF material. The peak at $\sim 220 \mathrm{~K}$ is due to the $\beta$-relaxation, a glass transition corresponding to the amorphous phase, relating to changes in the chain length distribution. The peaks at $\sim 236$ and $\sim 270 \mathrm{~K}$ are also related to the $\beta$-relaxation and can be explained through the hindering of the molecular motion by the crystallites. The $\beta$-related relaxations in the temperature range from $220 \mathrm{~K}$ to $320 \mathrm{~K}$ depend on vibration mode (longitudinal or shear), molecular structures (molecular weight, molecular weight distribution) and crystallinity [26]. The upper glass transitions, corresponding to the $\beta$-relaxations in the amorphous-crystalline interphase, appear in the temperature range of 300 $330 \mathrm{~K}$. Other relaxations above $330 \mathrm{~K}$ are related to the $\alpha$-relaxation processes corresponding to the phasemelting phenomena. The position of the melting temperature of each crystalline phase of the PVdF polymer has been studied [33]. We also must point out that the melting of $\gamma$-conformation occurs at temperatures higher than 
that of the $\alpha$ and $\beta$-conformation. Therefore, the PVdF polymer presents several internal friction peaks linked to the presence of several conformations and crystallites of different sizes on the melting.

As shown in Figure 8 and Figure 14, there are different temperature dependences of the internal friction on the PVdF binders of both positive and negative electrodes. These results indicate that there are different molecular structures, the concentration of the amorphous phase as well as the hollow voids in the PVdF binders of the positive and negative electrodes.

\subsubsection{Internal Friction on $\mathrm{LiMn}_{2} \mathrm{O}_{4}$ Microcrystal}

$\mathrm{LiMn}_{2} \mathrm{O}_{4}$ has spinel crystal structure with cubic symmetry at temperatures above $300 \mathrm{~K}$ [34] [35]. Below this temperature it becomes orthorhombic. This phase transition at room temperature has been demonstrated by several measurement methods such as differential scanning calorimetry (DSC) [36], electric resistance [36], infrared spectroscopy (IR) [37], and x-ray [38] and neutron [39] diffractions. The inelastic spectroscopy studies on the Young's modulus and the elastic energy loss function also showed that the cubic/orthorhombic transition of a sintered porous poly-crystalized $\mathrm{LiMn}_{2} \mathrm{O}_{4}$ sample, corresponding to a charge $\left(\mathrm{Mn}^{3+}\right.$ and $\left.\mathrm{Mn}^{4+}\right)$ ordering variation, can be detected in the temperature range of 290 - $305 \mathrm{~K}$ [40]. A thermally-activated relaxation peak centered at $100 \mathrm{~K}$ has also been observed by means of inelastic spectroscopy [41]. This relaxation process can be ascribed to the stress-induced charge jump from $\mathrm{Mn}^{3+}$ to $\mathrm{Mn}^{4+}$.

Inelastic behaviors of the polycrystalline $\mathrm{LiMn}_{2} \mathrm{O}_{4}$ sample synthesized by a solid-state reaction have been characterized using a vibrating-reed technique [42]. A phase transition due to an ordering of $\mathrm{Mn}^{3+}$ and $\mathrm{Mn}^{4+}$ ions were observed at a temperature of $290 \mathrm{~K}$. In general, the elastic behaviors of the $\mathrm{LiMn}_{2} \mathrm{O}_{4}$ materials depend strongly on crystal structure, volumes of amorphous phase and defects. Therefore, the internal friction peak is always asymmetric and much broad over a wide temperature range, 100 - $200 \mathrm{~K}$ [42].

The active materials of the positive electrode used in this study are composed of the $\mathrm{LiMn}_{2} \mathrm{O}_{4}$ and $\mathrm{LiCoNiAlO}_{2}$, carbon black, graphite nanoplatelets and the PVdF polymer. Hardness of the $\mathrm{LiMn}_{2} \mathrm{O}_{4}$ crystal and the PVdF polymer is $11 \mathrm{GPa}$ and $0.15 \mathrm{GPa}$, respectively [43] [44]. Under the same stress during vibration of the reed sample, the strain appeared in the PVdF polymer is much larger than that in the $\mathrm{LiMn}_{2} \mathrm{O}_{4}$ crystal, carbon black and graphite nanoplatelets. Therefore, the internal friction can be observed in the PVDF polymer more easily due to larger strain [45].

The nature of internal friction revealed in this study are not match to the results reported about the $\mathrm{LiMn}_{2} \mathrm{O}_{4}$ crystal, we can conclude that the internal friction peaks at $\sim 150, \sim 240$ and $\sim 410 \mathrm{~K}$ are related to the PVdF polymer.

\subsubsection{Internal Friction on Graphite and Diamond-Like Carbon}

Temperature dependence of the internal friction of bulk graphite material has been measured in the temperature range of $150-680 \mathrm{~K}$ [46]. Two internal friction peaks were observed at 385 and $620 \mathrm{~K}$ and their backgrounds has small temperature dependence only. The peak at $385 \mathrm{~K}$ is proved to originate from the sweeping motion of in-plane dislocations and is a relaxation-type peak. Other peak at $620 \mathrm{~K}$ is a transformation peak, resulting from the transformation of asphalt which is used as binder in preparation of bulk graphite.

Temperature dependences of the internal friction of nanocrystalline diamond-like carbon films in the range of $0.4-300 \mathrm{~K}$ showed that there is a peak at approximately $1.7 \mathrm{~K}$ and the internal friction increases monotonically with increasing temperature to $300 \mathrm{~K}$ [47]. The internal friction of amorphous diamond-like carbon films has also been measured at temperatures between $0.3 \mathrm{~K}$ and $300 \mathrm{~K}$ [48]. The internal friction increases with increasing temperature but no any peaks were observed in this temperature range despite the ratio of $s p^{3}$ to $s p^{2}$ component in the films was changed in a wide range.

\subsubsection{Internal Friction on Complex of Carbon with PVdF Binder}

Internal friction properties of a PVdF-graphite nanoplatelet composite have been reported [49]. The graphite nanoplatelets with average thickness of $50 \mathrm{~nm}$ and diameter of $10 \mu \mathrm{m}$ were introduced to the PVdF polymer in various concentrations. The $\beta$-relaxation process appeared in the $\mathrm{PVdF}$ polymer at $\sim 240 \mathrm{~K}$ was observed in the temperature range of $260-310 \mathrm{~K}$, and no any other relaxation related to the graphite nanoplatelet was detected. The $\beta$-relaxation in the composite is a thermally activated process with activation energy of $2.56 \mathrm{eV}$.

Nanocomposites of PVdF polymer with multiwalled carbon nanotubes (MWCNTs) have also been studied by measuring mechanical properties in a wide composition range [50]. The results showed that MWCNTs act as 
nucleation agent during crystallization and slightly increase the crystallinity of PVdF/MWCNT bulk films. In addition to the $\beta$-relaxation of the PVdF polymer at $\sim 233 \mathrm{~K}$, the internal friction peaks related to the MWCNTs were not observed at temperatures from $170 \mathrm{~K}$ to $300 \mathrm{~K}$. The transition temperature of the $\beta$-phase in the nanocomposites does not change with MWCNT concentration.

In Section 3.2.3, we have discussed the internal friction of carbon-related materials such as graphite, and the nanocrystalline and amorphous diamond-like carbon. Not internal friction peaks on these carbon related materials in the temperature range of $100-300 \mathrm{~K}$ have been reported. Therefore, we can conclude based on the above results that the internal friction peaks at $\sim 150, \sim 240$ and $\sim 413 \mathrm{~K}$ as shown in Figure 8, Figure 12 and Figure 14 are due to relaxation processes occurred in the PVdF binder in the positive electrode.

\subsubsection{Internal Friction on Al Metal and Its Alloys}

The internal frictions of pure $\mathrm{Al}$ metal and its alloys in wide temperature range have been reported by several groups [51]-[58]. Mechanisms of the internal friction in Al metal and its alloys are complex, depending of composition and physical condition such as structural deformation and annealing history. In the temperature range of $100-400 \mathrm{~K}$, the internal friction of Al metal may be mainly due to movement of point defects [54] [56], the interaction between dislocation with point defect [51] and impurity [55]. Therefore, the internal friction on the $\mathrm{Al}$ foil of the LiB in this study does not change after the charge/discharge cycling. Also, the internal friction on the $\mathrm{Al}$ foil is smaller than that from the active materials because the $30 \mu \mathrm{m} \mathrm{Al}$ foil is much thinner than that of the active materials, $160 \mu \mathrm{m}$. Therefore, we can conclude that the internal friction peaks at $\sim 150 \mathrm{~K}$ and $\sim 240 \mathrm{~K}$ as shown in Figure 8, Figure 12 and Figure 14 do not origin from the Al current detector of the positive electrode.

\subsection{Ageing Behaviors of the Positive Electrode}

The results in Figure 11 and Figure 12 show that the resonance frequency decreases $17 \%$ and $19 \%$ and the $\mathrm{Q}^{-1}$ value increases $40 \%$ and $16 \%$ at temperatures of 150 and $240 \mathrm{~K}$ after the charge/discharge of 150 cycles. Corresponding to the relaxation processes at $\sim 150$ and $\sim 240 \mathrm{~K}$, the activation energy increases $333 \%$ for the s-relaxation and $178 \%$ for the $\beta$-relaxation process, respectively. We have also measured the resistivity of the active materials of the positive electrode before and after the charge/discharge cycling. They are $650 \Omega \mathrm{cm}$ and $7.8 \times 10^{4} \Omega \mathrm{cm}$ before and after the cycling, namely, the resistivity of the active material of the positive electrode increases about 120 times after the cycling. One can notice from the above results that mechanical parameters of the resonance frequency and the internal friction as well as the activation energies of the internal friction relaxation processes are significant as valid parameters for characterizing the ageing behaviors of the positive electrode. The change in the activation energy due to the charge/discharge cycling may be related to a deposition of electrochemical reaction products on the surface of the active materials, which increase the contacting resistance between the active material particles coated by the PVdF binder. The changes in both structure and density of the PVdF polymer as well as the introduction of the impurities from the electrolyte and the active materials during the charge/discharge cycling also make difficult to the crystallization or the phase transition of the PVdF polymer. These effects appeared during the charge/discharge cycling increase the activation energy of the internal friction processes in the positive electrode.

\section{Conclusions}

Mechanical parameters of both resonance frequency and internal friction of the positive-electrode reed samples of the LiBs were measured in the temperature range of 100 - $400 \mathrm{~K}$. Two thermally-activated relaxation processes were observed at $\sim 150 \mathrm{~K}$ and $\sim 240 \mathrm{~K}$. They were related to the relaxation processes occurring in the $\mathrm{PVdF}$ binder of the positive electrode. The internal friction was due to a surface relaxation for the peak at $\sim 150$ $\mathrm{K}$ and a phase transition of the $\beta$ crystalline phase in the PVdF binder at $\sim 240 \mathrm{~K}$, respectively. Significant internal friction processes were not observed in the active materials of $\mathrm{LiMn}_{2} \mathrm{O}_{4}$ and the current collector of $\mathrm{Al}$ foil. The internal frictions observed in the PVdF binder may be due to larger strain in this organic polymer material when the vibration wave passes through it. The experimental results of the positive electrode before and after the charge/discharge of 150 cycles showed that the cycling process leads to decrease in the resonance frequency of the electrode samples and increase in their internal frictions. The activation energies of the internal friction processes increased after the charge/discharge cycling. The resonance frequency, the internal friction and the activation energy of the internal friction processes are expected as valid parameters for characterizing the ageing 
behaviors of positive electrode of the LiBs.

The mechanical parameters can be anticipated as effective indicators for characterizing ageing behaviors of the LiB electrode as a whole. By using this measurement technique, it becomes possible to enhance the cost-performance of the LiBs by matching each life times of positive and negative electrodes, separator and electrolyte. In addition, we must point out that there is not significant change on the capacity of the LiB after the charge/discharge of 150 cycles. This fact suggests that the increase of the internal fraction does not link directly to the decrease in the capacity of the LiB.

\section{Acknowledgements}

We are grateful to Professor Akira Namiki for fruitful discussions and valuable comments. The authors would also like to thank Mr. Jun Umemoto, Mr. Yusuke Hattori, Mr. Shyuji Yasuda and Mr. Shingo Furuta, Department of Applied Science for Integrated System Engineering, Kyushu Institute of Technology, for their help to get experimental data. This work is also partially supported by project No. 15-B01, Program of Research for the Promotion of Technological Seeds, Japan Science and Technology Agency (JST), as well as partially by Grant-in-Aid for Exploratory Research No: 23651115, Japan Society for the Promotion of Science (JSPS).

\section{References}

[1] Scrosati, B. and Garche, J. (2010) Lithium Batteries: Status, Prospects and Future. Journal of Power Sources, 195, 2419-2430. http://dx.doi.org/10.1016/j.jpowsour.2009.11.048

[2] Broussely, M., Biensan, Ph., Bonhomme, F., Blanchard, Ph., Herreyre, S., Nechev, K. and Staniewicz, R.J. (2005) Main Aging Mechanisms in Li Ion Batteries. Journal of Power Sources, 146, 90-96. http://dx.doi.org/10.1016/j.jpowsour.2005.03.172

[3] Barre, A., Deguilhem, B., Grolleau, S., Gerard, M., Suard, F. and Riu, D. (2005) A Review on Lithium-Ion Battery Ageing Mechanisms and Estimations for Automotive Applications. Journal of Power Sources, 241, 680-689. http://dx.doi.org/10.1016/j.jpowsour.2013.05.040

[4] Vetter, J., Novak, P., Wagner, M.R., Veit, C., Moller, K.C., Besenhard, J.O., Winter, M., Mehrens, M.W., Vogler, C. and Hammouche, A. (2005) Ageing Mechanisms in Lithium-Ion Batteries. Journal of Power Sources, 147, 269-281. http://dx.doi.org/10.1016/j.jpowsour.2005.01.006

[5] Meissner, E. and Richter, G. (2005) The Challenge to The Automotive Battery Industry: The Battery Has to Become an Increasingly Integrated Component within The Vehicle Electric Power System. Journal of Power Sources, 144, 438460. http://dx.doi.org/10.1016/j.jpowsour.2004.10.031

[6] Sarre, G., Blanchard, P. and Broussely, M. (2004) Aging of Lithium-Ion Batteries. Journal of Power Sources, 127, 6571. http://dx.doi.org/10.1016/j.jpowsour.2003.09.008

[7] Spotnitz, R. (2003) Simulation of Capacity Fade in Lithium-Ion Batteries. Journal of Power Sources, 113, 72-80. http://dx.doi.org/10.1016/S0378-7753(02)00490-1

[8] Arora, P., White, R.E. and Doyle, M. (1998) Capacity Fade Mechanisms and Side Reactions in Lithium-Ion Batteries. Journal of the Electrochemical Society, 145, 3647-3667. http://dx.doi.org/10.1149/1.1838857

[9] Broussely, M., Herreyre, S., Biensan, P., Kasztejna, P., Nechev, K. and Staniewicz, R.J. (2001) Aging Mechanism in Li Ion Cells and Calendar Life Predictions. Journal of Power Sources, 97-98, 13-21. http://dx.doi.org/10.1016/S0378-7753(01)00722-4

[10] Markosky, B., Rodkin, A., Cohen, Y.S., Palchik, O., Levi, E., Aurbach, D., Kim, H.J. and Schmidt, M. (2003) The Study of Capacity Fading Processes of Li-Ion Batteries: Major Factors That Play a Role. Journal of Power Sources, 119-121, 504-510. http://dx.doi.org/10.1016/S0378-7753(03)00274-X

[11] Raijmakersa, L.H.J., Danilova, D.L., van Lammerenb, J.P.M., Lammersb, M.J.G. and Notten, P.H.L. (2014) Sensorless Battery Temperature Measurements Based on Electrochemical Impedance Spectroscopy. Journal of Power Sources, 247, 539-544. http://dx.doi.org/10.1016/j.jpowsour.2013.09.005

[12] Troltzsch, U., Kanoun, O. and Trankler, H.R. (2006) Characterizing Aging Effects of Lithium Ion Batteries by Impedance Spectroscopy. Electrochimica Acta, 51, 1664-1672. http://dx.doi.org/10.1016/j.electacta.2005.02.148

[13] Song, J.Y., Lee, H.H., Wang, Y.Y. and Wan, C.C. (2002) Two- and Three-Electrode Impedance Spectroscopy of LithiumIon Batteries. Journal of Power Sources, 111, 255-267. http://dx.doi.org/10.1016/S0378-7753(02)00310-5

[14] Levi, M.D., Salitra, G., Markovsky, B., Teller, H., Aurbach, D., Heider, U. and Heider, L. (1999) Solid-State Electrochemical Kinetics of Li-Ion Intercalation into $\mathrm{Li}_{1-\mathrm{x}} \mathrm{CoO}_{2}$ : Simultaneous Application of Electroanalytical Techniques SSCV, PITT and EIS. Journal of the Electrochemical Society, 146, 1279-1289. http://dx.doi.org/10.1149/1.1391759 
[15] Rodrigues, S., Munichandraiah, N. and Shukla, A.K. (1999) AC Impedance and State-of-Charge Analysis of a Sealed Lithium-Ion Rechargeable Battery. Journal of Solid State Electrochemistry, 3, 397-405. http://dx.doi.org/10.1007/s100080050173

[16] Callens, A., Batist, R.D. and Eersels, L. (1976) Relaxational Behaviour of Polyvinylidene Fluoride. Il Nuovo Cimento $B$, 33, 434-446.

[17] Callens, A., Eersels, L. and Batist, R.D. (1978) Low Temperature Internal Friction on $\gamma$-Irradiated Polyvinylidene Fluoride (PVDF). Journal of Materials Science, 13, 1887-1900.

[18] Gregorio, J.R. and Capitao, R.C. (2000) Morphology and Phase Transition of High Melt Temperature Crystallized Poly(vinylidene fluoride). Journal of Materials Science, 35, 299-306. http://dx.doi.org/10.1023/A:1004737000016

[19] Kim, B.S., Lee, J.Y. and Porter, R.S. (1998) The Crystalline Phase Transformation of Poly(vinylidene fluoride)/ Poly(vinyl fluoride) Blend Films. Polymer Engineering Science, 38, 1359-1365. http://dx.doi.org/10.1002/pen.10306

[20] Samara, G.A. (1992) Pressure Dependence of the $\beta$ Molecular Relaxation Process and Dielectric Properties of Polyvinylidene Fluoride. Journal of Polymer Science Part B: Polymer Physics, 30, 669-679. http://dx.doi.org/10.1002/polb.1992.090300703

[21] Sajkiewicz, P. (1999) Crystallization Behaviour of Poly(vinylidene fluoride). European Polymer Journal, 35, 15811590. http://dx.doi.org/10.1016/S0014-3057(98)00242-0

[22] Hsu, T.C. and Geil, P.H. (1989) Deformation and Transformation Mechanisms of Poly(vinylidene fluoride) $\left(\mathrm{PVF}_{2}\right)$. Journal of Materials Science, 24, 1219-1232. http://dx.doi.org/10.1007/BF02397050

[23] Gregorio, J.R. and Ueno, E.M. (1999) Effect of Crystalline Phase, Orientation and Temperature on the Dielectric Properties of Poly(vinylidene fluoride) (PVDF). Journal of Materials Science, 34, 4489-4500. http://dx.doi.org/10.1023/A:1004689205706

[24] Sajkiewicz, P. (1994) Effects of an Electrostatic Field on Crystallization of Poly(vinylidene fluoride). Journal of Polymer Science Part B: Polymer Physics, 32, 313-323. http://dx.doi.org/10.1002/polb.1994.090320213

[25] Sajkiewicz, P., Wasiak, A. and Goclowski, Z. (1999) Phase Transitions during Stretching of Poly(vinylidene fluoride). European Polymer Journal, 35, 423-429. http://dx.doi.org/10.1016/S0014-3057(98)00136-0

[26] Guney, H.Y. (2005) Elastic Properties and Mechanical Relaxation Behaviors of PVDF (Poly(vinylidene fluoride)) at Temperatures between $-20^{\circ} \mathrm{C}$ and $100^{\circ} \mathrm{C}$ and at $2 \mathrm{MHz}$ Ultrasonic Frequency. Journal of Polymer Science Part B: Polymer Physics, 43, 2862-2873. http://dx.doi.org/10.1002/polb.20591

[27] Vinogradov, A.M. and Holloway, F. (2000) Dynamic Mechanical Testing of the Creep and Relaxation Properties of Polyvinylidene Fluoride. Polymer Testing, 19, 131-142. http://dx.doi.org/10.1016/S0142-9418(98)00079-8

[28] Linares, A. and Acosta, J.L. (1996) Dynamic Mechanical Properties of Binary and Ternary Blends Based on PVDF. Polymer Bulletin, 36, 241-247. http://dx.doi.org/10.1007/BF00294913

[29] Mohajir, B.E. and Heymans, N. (2001) Changes in Structural and Mechanical Behavior of PVDF with Processing and Thermomechanical Treatments. 1. Change in Structure. Polymer, 42, 5661-5667. http://dx.doi.org/10.1016/S0032-3861(01)00064-7

[30] Sencadas, V., Mendez, S.L., Serra, R.S., Balado, A.A. and Ribelles, J.L.G. (2012) Relaxation Dynamics of Poly(vinylidene fluoride) Studied by Dynamical Mechanical Measurements and Dielectric Spectroscopy. The European Physical Journal E, 35, 41. http://dx.doi.org/10.1140/epje/i2012-12041-x

[31] Mano, J.F., Sencadas, V., Costa, A.M. and Lanceros-Mendez, S. (2004) Dynamic Mechanical Analysis and Creep Behaviour of $\beta$-PVDF Films. Materials Science and Engineering: A, 370, 336-340. http://dx.doi.org/10.1016/j.msea.2002.12.002

[32] Ozkazanc, E., Guney, H.Y., Oskay, T. and Tarcan, E. (2008) The Effect of Uniaxial Orientation on the Dielectric Relaxation Behavior of $\alpha$-PVDF. Journal of Applied Polymer Science, 109, 3878-3886. http://dx.doi.org/10.1002/app.28617

[33] Gregorio, R. and Cestari Jr., M. (1994) Effect of Crystallization Temperature on the Crystalline Phase Content and Morphology of Poly(vinylidene fluoride). Journal of Polymer Science Part B: Polymer Physics, 32, 859-870. http://dx.doi.org/10.1002/polb.1994.090320509

[34] Rodriguez-Carvajal, J., Rousse, G., Masquelier, C. and Hervieu, M. (1998) Electronic Crystallization in a Lithium Battery Material: Columnar Ordering of Electrons and Holes in the Spinel LiMn $\mathrm{O}_{4}$. Physical Review Letters, 81, 4660-4663. http://dx.doi.org/10.1103/PhysRevLett.81.4660

[35] Yamada, A. and Tanaka, M. (1995) Jahn-Teller Structural Phase Transition around $280 \mathrm{~K}$ in $\mathrm{LiMn}_{2} \mathrm{O}_{4}$. Materials Research Bulletin, 30, 715-721. http://dx.doi.org/10.1016/0025-5408(95)00048-8

[36] Rousse, G., Masquelier, C., Rodriguez-Carvajal, J. and Hervieu, M. (1999) Cubic $\leftrightarrow$ Orthorhombic Transition in the Stoichiometric Spinel $\mathrm{LiMn}_{2} \mathrm{O}_{4}$. Electrochemical and Solid-State Letters, 2, 6-8. http://dx.doi.org/10.1149/1.1390716 
[37] Paolone, A., Roy, P., Rousse, G., Masquelier, C. and Rodriguez-Carvajal, J. (1999) Infrared Spectroscopy Investigation of the Charge Ordering Transition in $\mathrm{LiMn}_{2} \mathrm{O}_{4}$. Solid State Communications, 111, 453-458. http://dx.doi.org/10.1016/S0038-1098(99)00208-2

[38] Rousse, G., Masquelier, C., Rodriguez-Carvajal, J., Elkaim, E., Lauriat, J.P. and Martinez, J.L. (1999) X-Ray Study of the Spinel $\mathrm{LiMn}_{2} \mathrm{O}_{4}$ at Low Temperatures. Chemistry of Materials, 11, 3629-3635. http://dx.doi.org/10.1021/cm9910963

[39] Strobel, P., Cras, F.L., Seguin, L., Anne, M. and Tarascon, J.M. (1998) Oxygen Nonstoichiometry in Li-Mn-O Spinel Oxides: A Powder Neutron Diffraction Study. Journal of Solid State Chemistry, 135, 132-139. http://dx.doi.org/0.1006/jssc.1997.7611

[40] Paolone, A., Cantelli, R., Rousse, G., Masquelier, C. and Ferretti, M. (2003) Anelastic Spectroscopy Study of the Charge Order Transition of $\mathrm{LiMn}_{2} \mathrm{O}_{4}$. International Journal of Modern Physics B, 17, 799-804. http://dx.doi.org/10.1142/S0217979203016637

[41] Paolone, A., Cantelli, R., Rousse, G. and Masquelier, C. (2003) The Charge Order Transition and Elastic/Anelastic Properties of $\mathrm{LiMn}_{2} \mathrm{O}_{4}$. Journal of Physics: Condensed Matter, 15, 457-465. http://dx.doi.org/10.1088/0953-8984/15/3/310

[42] Sugiyama, J., Tamura, T. and Yamauchi, H. (1995) Elastic/Anelastic Behavior during the Phase Transition in Spinel $\mathrm{LiMn}_{2} \mathrm{O}_{4}$. Journal of Physics: Condensed Matter, 7, 9755-9764. http://dx.doi.org/10.1088/0953-8984/7/50/010

[43] Liu, Y., Sun, Y., Zeng, F., Liu, J. and Ge, J. (2013) Effect of POSS Nanofiller on Structure, Thermal and Mechanical Properties of PVDF Matrix. Journal of Nanoparticle Research, 15, 2116. http://dx.doi.org/10.1007/s11051-013-2116-1

[44] Amanieu, H., Rosato, D., Sebastiani, M., Massimi, F. and Lupascu, D.C. (2014) Mechanical Property Measurements of Heterogeneous Materials by Selective Nanoindentation: Application to $\mathrm{LiMn}_{2} \mathrm{O}_{4}$ Cathode. Materials Science and Engineering: A, 593, 92-102. http://dx.doi.org/10.1016/j.msea.2013.11.044

[45] Wang, Q.Z., Lu, D.M., Cui, C.X., Yan, N.J. and Wang, Q. (2013) Fabrication and Internal Friction Behaviors of Novel Porous CuAlMn Shape Memory Alloy Filled with Polystyrene. Materials Letters, 92, 82-85. http://dx.doi.org/10.1016/j.matlet.2012.10.071

[46] Wei, J.N., Huang, T.C., Zhao, L., Yu, J.M., Xie, W.J. and Li, G.M. (2008) Internal Friction Characterization of Graphite. Journal of Materials Science, 43, 5470-5473. http://dx.doi.org/10.1007/s10853-008-2824-6

[47] Metcalf, T.H., Liu, X., Houston, B.H., Baldwin, J.W., Butler, J.E. and Feygelson, T. (2005) Low Temperature Internal Friction in Nanocrystalline Diamond Films. Applied Physics Letters, 86, Article ID: 081910. http://dx.doi.org/10.1063/1.1868065

[48] Liu, X., Metcalf, T.H., Mosaner, P. and Miotello, A. (2005) Microstructure Dependence of Low-Temperature Elastic Properties in Amorphous Diamond like Carbon Films. Physical Review B, 71, Article ID: 155419. http://dx.doi.org/10.1103/PhysRevB.71.155419

[49] Li, Y.C., Tjong, S.C. and Li, R.K.Y. (2010) Electrical Conductivity and Dielectric Response of Poly(vinylidene fluoride) - Graphite Nanoplatelet Composites. Synthetic Metals, 160, 1912-1919. http://dx.doi.org/10.1016/j.synthmet.2010.07.009

[50] Huang, W., Edenzon, K., Fernandez, L., Razmpour, S., Woodburn, J. and Cebe, P. (2010) Nanocomposites of Poly(vinylidene fluoride) with Multiwalled Carbon Nanotubes. Journal of Applied Polymer Science, 115, 3238-3248. http://dx.doi.org/10.1002/app.31393

[51] Hasiguti, R.R., Igata, N. and Kamoshita, G. (1962) Internal Friction Peaks in Cold-Worked Metals. Acta Metallurgica, 10, 442-447. http://dx.doi.org/10.1016/0001-6160(62)90023-8

[52] Lax, E. and Filson, D.H. (1959) Second Low-Temperature Peak in the Internal Friction of Aluminum. Physical Review, 114, 1273-1273. http://dx.doi.org/10.1103/PhysRev.114.1273

[53] Bruner, L.J. (1960) Low-Temperature Internal Friction in Face-Centered Cubic and Body-Centered Cubic Metals. Physical Review, 118, 399-410. http://dx.doi.org/10.1103/PhysRev.118.399

[54] Baxter, W.J. and Wilks, J. (1963) The Effect of Annealing on the Bordoni Peak in Aluminum. Acta Metallurgica, 11, 978-982. http://dx.doi.org/10.1016/0001-6160(63)90067-1

[55] Chevalier, J.L., Peguin, P., Perez, J. and Gobin, P. (1972) Frottementintérieur de l'aluminiumtrèsfaiblementécroui. Journal of Physics D: Applied Physics, 5, 777-781. http://dx.doi.org/10.1088/0022-3727/5/4/319

[56] Mongy, M., Salama, K. and Beckman, O. (1963) Dislocation Relaxation in Aluminum. Solid State Communications, 1, 234-236. http://dx.doi.org/10.1016/0038-1098(63)90015-2

[57] Wei, J.N., Gong, C.L., Cheng, H.F., Zhou, Z.C., Li, Z.B., Shui, J.P. and Han, F.S. (2002) Low-Frequency Damping Behavior of Foamed Commercially Pure Aluminum. Materials Science and Engineering: A, 332, 375-381. http://dx.doi.org/10.1016/S0921-5093(01)01950-5 
[58] Golyandin, S.N., Sapozhnikov, K.V., Emel'yanov, Y.A., Sinani, A.B., Kustov, S.B. and Robinson, W.H. (1998) Influence of Temperature and Strain on the Amplitude-Dependent Internal Friction of High-Purity Aluminum. Physics of the Solid State, 40, 1667-1671. http://dx.doi.org/10.1134/1.1130631 
Scientific Research Publishing (SCIRP) is one of the largest Open Access journal publishers. It is currently publishing more than 200 open access, online, peer-reviewed journals covering a wide range of academic disciplines. SCIRP serves the worldwide academic communities and contributes to the progress and application of science with its publication.

Other selected journals from SCIRP are listed as below. Submit your manuscript to us via either submit@scirp.org or Online Submission Portal.
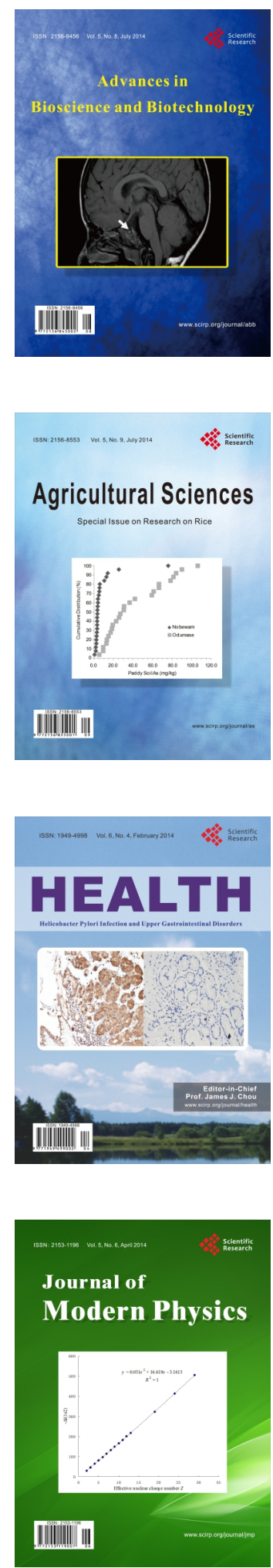
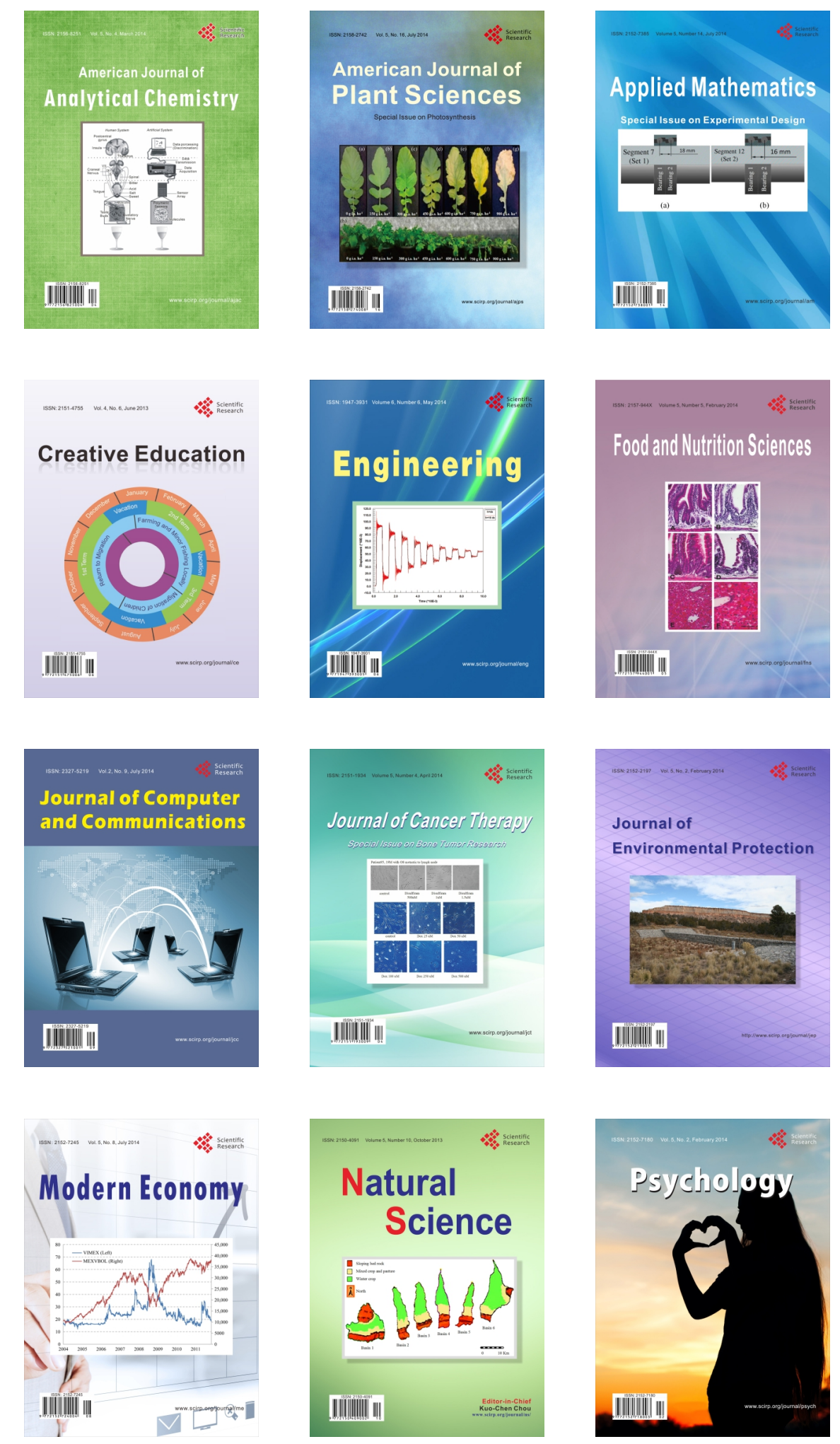